\title{
A NOVEL APPROACH FOR LIGHTFAST WET-WHITE LEATHER MANUFACTURE BASED ON SULFONE SYNTAN-ALUMINIUM TANNING AGENT COMBINATION TANNAGE
}

\section{Long Zhang ${ }^{1}$, Xinyu Zhao ${ }^{2}$, Chunhua Wang ${ }^{3}$, Wei Lin $^{4}$}

Key Laboratory of Leather Chemistry and Engineering of Ministry of Education, College of Biomass Science and Engineering, Sichuan University, Chengdu, China, 610065

Department of Biomass and Leather Engineering, College of Biomass Science and Engineering, Sichuan University, Chengdu, China, 610065

Herein, we have investigated a novel combination tannage for lightfast wet-white leather based on sulfone syntan and aluminium tanning agent. By optimizing the technology, $10 \%$ sulfone syntan $(B C)$ and $3 \%$ aluminium tanning agent $(B N)$ at final $\mathrm{pH}$ 4,0-4,5 can raise the shrinkage temperature (Ts) of the wet-white leather to $\sim 81^{\circ} \mathrm{C}$. Scanning electron microscope-Energy dispersive $X$-ray spectroscopy (SEM-EDX) results reveal that sulfone syntan and aluminium tanning agent can be evenly bound within the leather matrix, and promote the formation of tightly woven networks of collagen fibres. The novel combination tanning approach not only improves light fastness and lighter shade, but also confers high physical and mechanical properties to the wet-white leather.

Keywords: wet-white leather, sulfone syntan, aluminium tanning agent, combination tannage, light fastness.

\subsection{BC-BN combination tannage}

Note that when the dosage of $\mathrm{BN}$ increases from $3 \%$ to $5 \%$, the $T \mathrm{~s}$ of the combination tanned leather increases slightly, but its uptake does not increase anymore, and even decreases instead. Therefore, 10\% BC and 3\% $\mathrm{BN}$ are used in the subsequent combination tanning experiments, which can

\footnotetext{
${ }^{1}$ Long Zhang - Key Laboratory of Leather Chemistry and Engineering of Ministry of Education, College of Biomass Science and Engineering, Sichuan University, Chengdu, China, 61006

${ }^{2}$ Xinyu Zhao - Department of Biomass and Leather Engineering, College of Biomass Science and Engineering, Sichuan University, Chengdu, China, 610065

${ }^{33}$ Chunhua Wang - Department of Biomass and Leather Engineering, College of Biomass Science and Engineering, Sichuan University, Chengdu, China, 610065, e-mail: wangchunhua@scu.edu.cn; wlin@scu.edu.cn

${ }^{4}$ Wei Lin - Key Laboratory of Leather Chemistry and Engineering of Ministry of Education, College of Biomass Science and Engineering, Sichuan University, Chengdu, China, 61006, email:wlin@scu.edu.cn
} 
confer the wet-white leather with shrinkage temperature of $\sim 81^{\circ} \mathrm{C}$. The duration of most leather manufacture processes is determined by the duration of penetration of chemicals through the skin layers, as the interaction of chemicals with the dermis is much faster than those substances are absorbed into the skin. For this reason, a lot of effort is being put into developing methods or equipment for hide/leather treatment that would speed up the penetration of solutions into the skin.

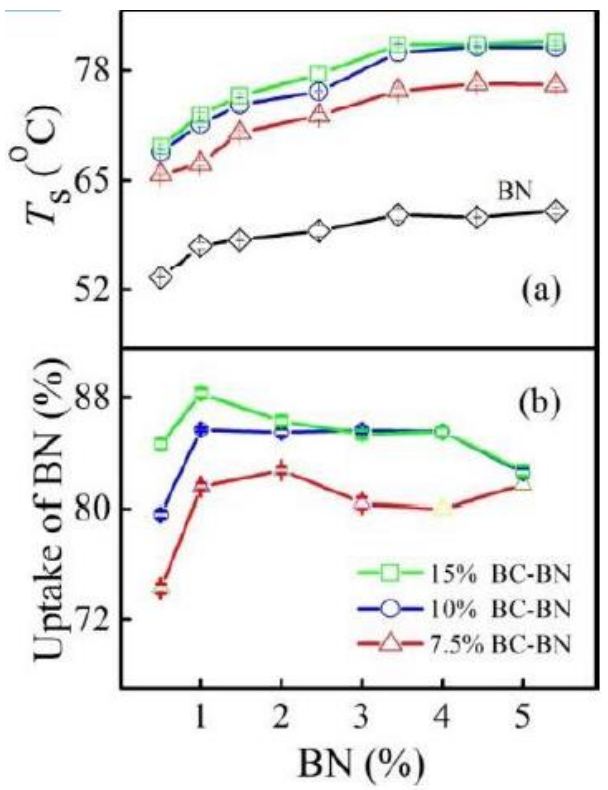

Figure 1 - Ts of wet-white leathers (a) and uptake of BN (b) as a function of $\mathrm{BN}$ dosage

Figure 2 shows the effect of final $\mathrm{pH}$ on $T \mathrm{~s}$ of wet-white leathers. It is clear that $\mathrm{pH}$ ranging from $4,0-4,5$ can mostly benefit the improvement in $T \mathrm{~s}$. Therefore, the final $\mathrm{pH}$ of $4,0-4,5$ is preferred in the combination tannage. 


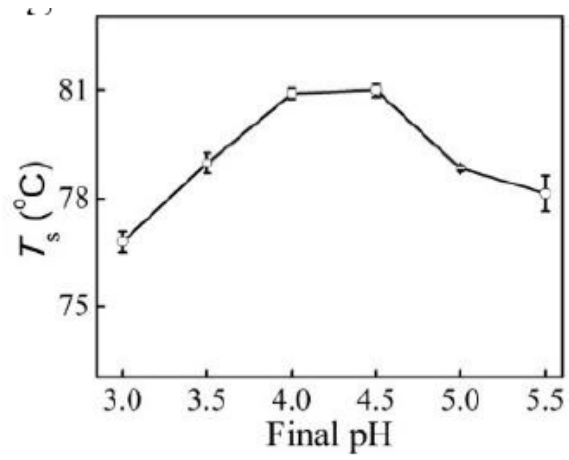

Figure 2 - $T \mathrm{~s}$ of combination tanned leathers as a function of final $\mathrm{pH}$

\subsection{SEM-EDX analysis}

As can be seen from Figure 3a, solo BC tanned collagen fibres are closely woven with each other to form a stratified collagen fibre bundles. At a higher magnification level (Figure 3b), it shows clear fibrils with smooth surface. After the introduction of BN (Figure3c and d), the combination tanned collagen fibres are more tightly woven due to the effect of $\mathrm{Al} 3+$ tanning agent.

The distribution of tanning agents in collagen fibres was also studied as shown in the corresponding EDX spectra (Figure 4). Both sulfur (S) and aluminium ( $\mathrm{Al}$ ), the feature elements in $\mathrm{BC}$ and $\mathrm{BN}$, respectively, are homogeneously distributed in the vertical section of the wet-white leather, demonstrating that $\mathrm{BC}$ and $\mathrm{BN}$ can uniformly penetrate into leather matrix. It can be expected that a reasonable good wet-white leather properties can be resulted.
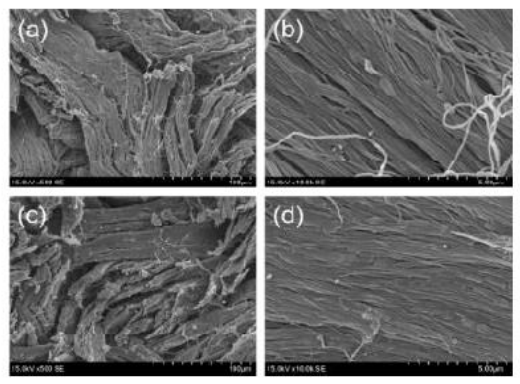

Figure 3 - SEM images of cross sections of solo $\mathrm{BC}$ tanned leather (a and b) and BC-BN combination tanned leather ( $c$ and d) 


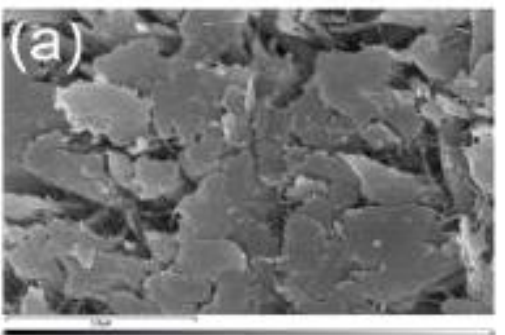

O Kal
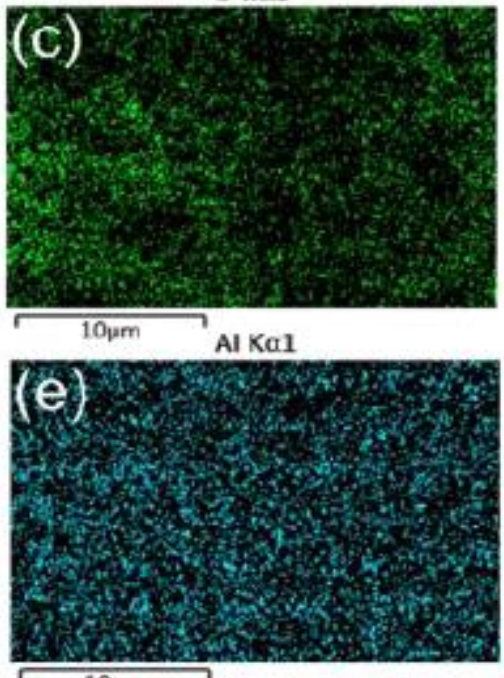

$10 \mathrm{~mm}$
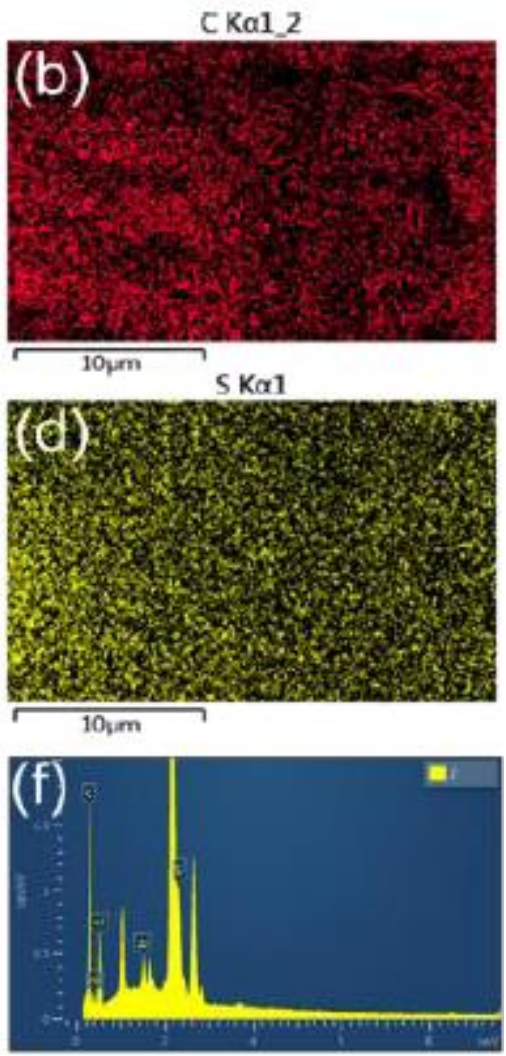

Figure 4 - SEM image of vertical section of the BC-BN combination tanned leather (a); EDX elemental mappings of carbon (b), oxygen (c), sulfur (d) and aluminium (e); and corresponding EDX spectrum (f)

\subsection{Color analysis}

Compared with solo $\mathrm{BC}$ tanning, the $\mathrm{BC}-\mathrm{BN}$ combination tanned leather gives a lighter shade, as indicated in the $L^{*}$ value (Figure 5a). Light fastness is assessed by the exposure of the wet-white leathers in UV irradiation. 1 It can be seen that the $L^{*}$ value of the combination tanned leather is always higher, whereas the color difference $(\Delta E)$ is lower (Figure $5 b$ ) for an extended irradiation time, suggesting that the introduction of $\mathrm{BN}$ can endow wet-white leathers with better light fastness. A solution with the following composition was used to study the unhairing process: $\mathrm{NaCl} 80$ 
$\mathrm{g} / \mathrm{l}, \mathrm{NaOH}(100 \%)-100 \mathrm{~g} / \mathrm{l}, \mathrm{Na}_{2} \mathrm{~S}(100 \%)-80 \mathrm{~g} / \mathrm{l}$. The samples were treated by the solution in two ways.

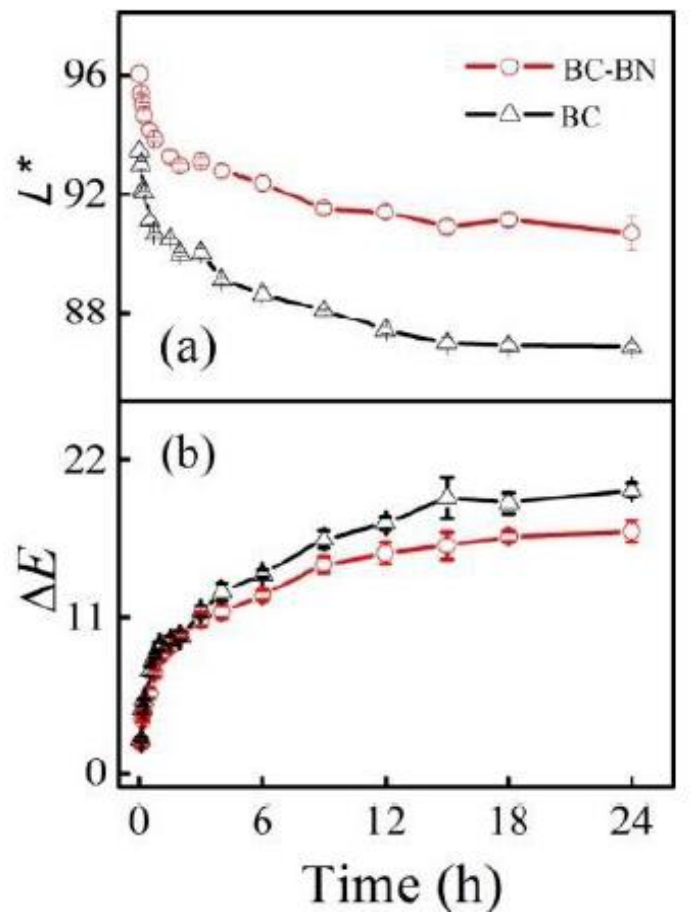

Figure $5-L^{*}$ (a) and $\Delta E$ (b) of wet-white leathers under $\mathrm{UV}$ radiation for $24 \mathrm{~h}$

\subsection{Physical and mechanical properties measurements}

Table I - Physical and mechanical properties of BC-BN combination tanned leathers

\begin{tabular}{|l|c|c|}
\hline \multicolumn{1}{|c|}{ Parameters } & $\begin{array}{c}\text { BC-BN } \\
\text { tanned leathers }\end{array}$ & $\begin{array}{c}\text { Standard for shoe up- } \\
\text { per leather }\end{array}$ \\
\hline Tensile strength $(\mathrm{MPa})$ & $17,2 \pm 1,3$ & - \\
\hline Tear strength $(\mathrm{N})$ & $40,0 \pm 1,6$ & $\geq 20$ \\
\hline Elongation at $10 \mathrm{~N}(\%)$ & $16,9 \pm 2,4$ & $\leq 40$ \\
\hline Bursting strength $(\mathrm{N} / \mathrm{mm})$ & $207,4 \pm 3,8$ & $\geq 200$ \\
\hline$T s\left({ }^{\circ} \mathrm{C}\right)$ & $80,9 \pm 0,4$ & $\geq 80$ \\
\hline
\end{tabular}


Table presents physical and mechanical properties of the wet-white leather tested with the official methods recommended by IULTCS. All of these physical and mechanical properties can meet the Chinese standard requirements for shoe upper leather2. It suggests that the $\mathrm{BC}-\mathrm{BN}$ combination tannage is a promising approach and can be applied in shoe upper leather manufacture.

\section{Conclusions}

In the present study, a novel combination tanning approach based on $\mathrm{BC}$ and $\mathrm{BN}$ for lightfast wet-white leather manufacture has been established. The $10 \%$ of $\mathrm{BC}$ and $3 \% \mathrm{BN}$ at final $\mathrm{pH} 4,0-4,5$ can endow the leather with $T \mathrm{~s}$ above $80^{\circ} \mathrm{C}$. Both of the two are evenly bound within the the leather matrix, and make the collagen fibres isolated and compact. The introduction of $\mathrm{BN}\left(\mathrm{Al}^{3+}\right)$ into $\mathrm{BC}$ (sulfone syntan) gives it lighter shade and better light fastness. The combination tanned leathers have reasonable good physical and mechanical properties that can meet official standard requirements for shoe upper leather.

\section{References}

1.Ozgunay H.; Lightfastness properties of leathers tanned with various vegetable tannins. J. Am. Leather Chem. Assoc. 103, 345-351, 2008.

2. Chen, R., H., Chen, R., S.; QB/T 1873-2010: shoe upper leather, China Light Industry Press, Beijing China, pp. 1-4, 2010. 9. Beschleunigte Technik bei der Entwollung // Leder, 1997, 48, 9, P. 198-201. 